\title{
Induction of ovulation in hens by an analogue of LH-RH
}

\author{
Katuhide Tanaka and M. Kamiyoshi \\ Department of Poultry and Animal Sciences, Gifu University, Kakamigahara, Gifu, Japan
}

Fujino et al. (1972) have synthesized a nonapeptide amide with the structure, (pyro)Glu-His-TrpSer-Tyr-Gly-Leu-Arg-Pro-ethylamine, which is an analogue of LH-RH. This analogue has been shown to be more effective than LH-RH in causing the release of LH and FSH from the pituitary of rats (Fujino et al., 1972; Arimura, Vilchez-Martinez \& Schally, 1974) and man (Nakano, Takekida, Kotsuji, Miyazaki \& Tojo, 1974), and in inducing ovulation in rats and rabbits (Fujino et al., 1973). This paper reports a comparison of the ovulation-inducing activity in hens between synthetic LH-RH and the analogue.

The synthetic LH-RH (Eisai Co. Ltd, Tokyo, Japan) and the analogue (Takeda Chemical Industries, Tokyo, Japan) were dissolved in sterilized distilled water. They were injected into the pectoral muscle of White Leghorn hens $(2 \cdot 0-2 \cdot 4 \mathrm{~kg}$ body wt, 17 months of age) which had been laying eggs in a regular sequence of more than three eggs with 1 day pause between sequences. The injection was given at 15.00-16.00 hours on the day of laying the terminal egg of the sequence, i.e. $14 \mathrm{hr}$ before expected ovulation of the initial egg of the sequence. Control birds received a water injection only, and the doses are shown in Table 1 . The volume of injection was $0.5 \mathrm{ml}$. Twelve to thirteen hours after the injection (1-2 hr before natural ovulation), digital palpations of the oviduct through the cloaca were performed by three separate observers, who had no knowledge of which treatment the hen had received, to estimate the incidence of ovulation. The reliability of the technique was established in an earlier study (Tanaka, Kamiyoshi \& Wolford, 1970) in which ovulation was confirmed at autopsy. When an ovum was detected by palpation, the hens were regarded as ovulating prematurely. Oviposition was also checked and was regarded as confirming premature ovulation if it occurred before 05.00 hours since the normal time of oviposition in this flock was 06.00 hours.

Table 1. Effect of synthetic LH-RH and its analogue, (Des-Gly- $\mathrm{NH}_{2}{ }^{10}$, Pro-ethylamide $\left.^{9}\right)-\mathrm{LH}-\mathrm{RH}$, on the induction of premature ovulation in hens

\begin{tabular}{clcccc}
\hline & & Dose & No. of hens & \multicolumn{2}{c}{ Hens ovulating prematurely } \\
\cline { 5 - 6 } injected & & No. & $\%$ \\
\hline 1 & LH-RH & $2 \cdot 5$ & 15 & 0 & 0 \\
2 & LH-RH & 5 & 16 & 1 & $6 \cdot 3$ \\
3 & LH-RH & 10 & 31 & 8 & $25 \cdot 8$ \\
4 & LH-RH & 20 & 32 & 13 & $40 \cdot 6$ \\
5 & LH-RH & 40 & 27 & 18 & $66 \cdot 7$ \\
6 & Analogue & $2 \cdot 5$ & 32 & 5 & $15 \cdot 6$ \\
7 & Analogue & 5 & 32 & 16 & $50 \cdot 0$ \\
8 & Analogue & 10 & 29 & 21 & $72 \cdot 4$ \\
9 & Analogue & 20 & 28 & 25 & $89 \cdot 3$ \\
10 & Water & - & 30 & 0 & 0 \\
\hline
\end{tabular}

Significance of difference $(P<0 \cdot 01)$ by $\chi^{2}$-test with Yates' correction: Group 3 versus Group 10; Group 3 versus Group 5; Group 3 versus Group 8; Group 7 versus Group 10; Group 7 versus Group 9; Group 4 versus Group 9.

The results are shown in Table 1 . The injection of $10 \mu \mathrm{g} \mathrm{LH-RH}$ induced a premature ovulation in about one-third of the birds, while the injection of $5 \mu \mathrm{g}$ of the analogue induced ovulation in half of the birds. The incidence of premature ovulation increased with the higher doses. The results indicate that the analogue is more potent than the synthetic LH-RH for the induction of ovulation in hens. 
We thank Eisai Co. Ltd for the synthetic LH-RH and the Takeda Chemical Industries, Ltd for [Des-Gly- $\mathrm{NH}_{2}{ }^{10}$, Pro-ethylamide ${ }^{9}$-LH-RH.

\section{References}

Arimura, A., Vilchez-Martinez, J.A. \& Schally, A.V. (1974) In vitro comparison of LH-RH and FSH-RH activities of $\left(\right.$ Des-Gly $\left.{ }^{10}\right)$ (Pro 9 -ethylamide)LH-RH, (Des-Gly $\left.{ }^{10}\right)\left(\right.$ Pro $^{9}$-propylamide)-LH-RH, and LH-RH using immature male rats. Proc. Soc. exp. Biol. Med. 146, 17-20.

Fujino, M., Kobayashi, S., Obayashi, M., Shinagawa, S., Fukuda, T., Kitada, C., NaKayama, R., Yamazaki, I., White, W.F. \& RipPeL, R.H. (1972) Structure-activity relationships in the C-terminal part of luteinizing hormone releasing hormone (LH-RH). Biochem. Biophys. Res. Commun. 49, 863-869.

Fujino, M., Shinagawa, S., Yamazaki, I., Kobayashi,
M., Fukuda, T., Nakayama, R., White, W.F. \& RipPel, R.H. (1973) (Des-Gly-NH ${ }_{2}^{20}$, Pro-ethyl-

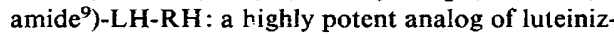
ing hormone releasing hormone. Archs Biochem. Biophys. 154, 488-489.

Nakano, R., Takekida, H., Kotsuji, F., Miyazaki, Y. \& Tojo, S. (1974) Gonadotropin response to a new analogue of luteinizing hormone-releasing factor, (des-Gly- $\mathrm{NH}_{2}{ }^{10}$, Pro-ethylamide ${ }^{9}$ )-LRF, in men. J. clin. Endocr. Metab. 39, 802-804.

TANAKA, K., KamiYoshi, M. \& Wolford, J.H. (1970) A possible role of $\mathrm{LH}$ released soon after ovulation for succeeding ovulation in the hen. Poult. Sci. 49, 1692-1697.

Received 30 May 1975 